\title{
Biokonversi Serat Kelapa Sawit Menjadi Glukosa dengan Diluted-Acid Hydrothermal Treatment
}

\author{
Iryanti Fatyasari Nata ${ }^{\bowtie}$, Norlina, Mira Pangesti
}

DOI 10.15294/jbat.v4i2.5264

Program Studi Teknik Kimia, Universitas Lambung Mangkurat

J1. A. Yani Km. 36, Banjarbaru, Kalimantan Selatan 70714 Indonesia

\begin{tabular}{l} 
Article Info \\
\hline Sejarah Artikel: \\
Diterima Maret \\
2016 \\
Disetujui April 2016 \\
Dipublikasikan Juni \\
2016 \\
\hline Keywords: \\
crude palm oil, diluted- \\
acid, fiber cake, \\
glucose, hydrothermal \\
treatment \\
\hline
\end{tabular}

\begin{abstract}
Abstrak
Fiber cake merupakan salah satu limbah yang dihasilkan oleh industri minyak kelapa sawit (CPO). Limbah ini dapat dikurangi dengan memanfaatkan fiber cake (FC) sebagai bahan baku pembuatan bioetanol. FC merupakan Palm Kernel Press Cake (PKC) yaitu residu dari esktraksi palm oil yang mengandung 57,9\% selulosa dan 18\% klason lignin dan 14,94\% hemiselulosa. Penelitian ini bertujuan untuk menentukan pengaruh konsentrasi fiber cake dan waktu terhadap konsentrasi glukosa yang dihasilkan, mengetahui struktur morphology dan kristalinitas fiber cake sebelum dan sesudah hydrothermal treatment. Serat kelapa sawit dihidrolisis dengan reaktor hydrothermal menggunakan katalis $\mathrm{H}_{2} \mathrm{SO}_{4} 2 \%(\mathrm{v} / \mathrm{v})$ dan pada $150{ }^{\circ} \mathrm{C}$ selama 2 jam. Variasi konsentrasi fiber cake yaitu $2,5 \% ; 5 \% ; 7,5 \%$ dan $10 \% \mathrm{w} / \mathrm{v}$ dan variasi waktu selama 1, 2, 3 dan 4 jam. Kadar glukosa tertinggi pada konsentrasi FC 2,5\% dengan waktu 3 jam sebesar 2,336 $\pm 0,015 \mathrm{mg} / \mathrm{mL}$. Hasil analisis Scanning electron microscope (SEM) dan X-Ray Diffraction (XRD) dapat diketahui struktur permukaan yang halus menjadi pecah dan kasar. Setelah proses hidrolisis peningkatan struktur kristal fiber cake dari $27,57 \%$ menjadi $31,15 \%$.
\end{abstract}

\begin{abstract}
Fiber cake (FC) is a one of effluent of Crude Palm Oil (CPO) industry. This effluent can be decreased by using FC for bioethanol production. FC is actually Palm Kernel Press Cake (PKC) a residue of palm oil extraction, which containing $57.9 \%$ cellulose and $18 \%$ klason lignin, and containing $14.94 \%$ hemicellulose. This study aimed to determined the effect of fiber concentrations and reaction time for glucose production to investigate the structure of morphology and crystalinity of the fiber cake before and after hydrothermal treatment. Fiber cake was treated by hydrothermal reactor using catalysts $2 \%$ $\mathrm{H}_{2} \mathrm{SO}_{4}(\mathrm{v} / \mathrm{v})$ and $150^{\circ} \mathrm{C}$ for 2 hour. Variations concentration of fiber cake which is $2.5 \%$; $5 \%$; $7.5 \%$ and $10 \% \mathrm{w} / \mathrm{v}$ and time variations for 1, 2, 3 and 4 hours. The highest glucose concentration was found at $2.5 \%$ FC for 3 hour about $2.336 \pm 0.015 \mathrm{mg} / \mathrm{mL}$. Scanning electron microscope (SEM) and $X$ Ray Diffraction (XRD) analysis result shown that the surface is transformed become cracked and rough due to hydrolysis process and also improvement of the crystal structure of fiber cake from $27.57 \%$ to $31.15 \%$.
\end{abstract}

(C) 2016 Semarang State University

\footnotetext{
Corresponding author:

Program Studi Teknik Kimia, Universitas Lambung Mangkurat

Jl. A. Yani Km. 36, Banjarbaru,

Kalimantan Selatan 70714 Indonesia

E-mail: ifnata@unlam.ac.id
} 


\section{PENDAHULUAN}

Indonesia adalah penghasil minyak kelapa sawit terbesar di dunia, dengan penyebaran hampir di seluruh pulau di Indonesia, termasuk Kalimantan. Kalimantan Selatan sangat berpotensi dalam pengembangan perkebunan kelapa sawit. Luas area tanaman kelapa sawit di Kalimantan Selatan mencapai $50.166 \mathrm{Ha}$, terdiri dari perkebunan rakyat $107.118 \mathrm{Ha}$, perkebunan besar swasta $237.769 \mathrm{Ha}$ dan perkebunan besar negara $4.865 \mathrm{Ha}$ (ICN, 2011). Dalam pengolahan minyak kelapa sawit atau crude palm oil (CPO) menghasilkan limbah serat kelapa sawit (fiber cake). Pabrik minyak kelapa sawit memproduksi hasil samping sebanyak 0,70 ton $/ \mathrm{m}^{3}$ serat, 0,35 ton $/ \mathrm{m}^{3}$ tempurung dan 1,1 ton $/ \mathrm{m}^{3}$ tandan kosong untuk menghasilkan 1 ton $/ \mathrm{m}^{3}$ minyak sawit mentah (Rosdanelli \& Daud, 2004). Palm kernel press cake (PKC) yang merupakan residu dari dari esktraksi palm oil mengandung sekitar 7-9\% glukosa dan 30$35 \%$ karbohidrat (Karakashev et al., 2007). Limbah industri kelapa sawit khususnya serat, memiliki potensi yang besar sebagai sumber biomassa selulosa yang dapat dikonversi menjadi glukosa dan dengan proses lanjutan dapat dijadikan sebagai bahan baku pembuatan bioetanol. Pemanfaatan serat kelapa sawit ini dapat mengurangi limbah yang diproduksi setiap harinya. Penelitian tentang pemanfaatan limbah industri kelapa sawit ini telah dilakukan, seperti pembuatan bioetanol dari palm kernel press cake (PKC) dengan hidrolisis enzim dan fermentasi menghasilkan glukosa sebesar 53\% dan etanol 52\% (Sluiter, 2006). Teknik hydrothermal untuk hidrolisis terhadap ampas tebu telah berhasil dilakukan dengan menghasilkan xylose (Boussarsar et al., 2009). Biokonversi selulosa dari serat kelapa sawit dengan hydrothermal treatment telah dilakukan, dimana hasil optimum yang dicapai pada konsentrasi $\mathrm{H}_{2} \mathrm{SO}_{4} 2 \%$ pada suhu 150 ${ }^{0} \mathrm{C}$ dengan konsentrasi glukosa $1,36 \mathrm{mg} / \mathrm{mL}$ melalui proses hidrolisis (Khairunnisa \& Fatimah, 2012).

Penelitian ini memfokuskan pada pemanfaatan serat kelapa sawit, optimasi kondisi operasi produksi glukosa dari serat kelapa sawit sehingga dihasilkan kandungan glukosa yang tinggi, dengan harapan untuk tahap selanjutnya produksi bioetanol akan meningkat pula. Untuk itu perlu ditinjau kembali waktu hydrothermal dan rasio serat terhadap larutan (liquid-solid ratio, LSR).
Dengan variabel proses di atas diharapkan kadar glukosa yang dihasilkan akan meningkat. Hal yang diamati pada penelitian ini adalah menentukan pengaruh waktu hydrothermal dan konsentrasi fiber cake pada proses hidrolisis untuk mendapatkan konsentrasi glukosa yang tinggi dan mengetahui perubahan struktur morphology dan kritalinitas serat kelapa sawit setelah hydrothermal treatment. Dengan penelitian ini diharapkan dapat mengurangi limbah dan memberikan nilai ekonomis pada limbah serat kelapa sawit sebagai hasil samping pengolahan industri pengolahan CPO.

\section{METODE PENELITIAN}

Bahan-bahan yang digunakan adalah serat kelapa sawit (SKS) yang didapat dari PT. Kahuripan Inti Sawit industri CPO (Crude Palm Oil) Kintap, Kalimantan Selatan, aquadest, asam sulfat $\left(\mathrm{H}_{2} \mathrm{SO}_{4}\right)$, natrium hidroksida $(\mathrm{NaOH})$, indikator metil biru, Fehling A dan Fehling B.

\section{Acid Hydrolysis Treatment}

SKS dikeringkan dalam oven pada suhu $70{ }^{\circ} \mathrm{C}$ selama 8 jam, selanjutnya dihaluskan dan diayak hingga didapatkan ukuran \pm 250 mikron. SKS yang telah dihaluskan $(2,5 \%, 5 \%, 7,5 \%$, dan $10 \% \mathrm{w} / \mathrm{v})$ ditambahkan aquadest $(30 \mathrm{~mL})$, setelah itu dilakukan acid hydrolysis treatment dalam reaktor hydrotermal menggunakan katalis $\mathrm{H}_{2} \mathrm{SO}_{4}$ dengan konsentrasi $2 \%$ dan suhu $150{ }^{\circ} \mathrm{C}$, selama $1,2,3$ dan 4 jam. Larutan yang didapat kemudian disaring, filtratnya dianalisis untuk menentukan kadar glukosa.

\section{Karakterisasi dan Analisis sampel}

Analisis kandungan glukosa dengan metode Fehling (SNI 01-2891-1992). Untuk mengetahui struktur dan morfologi sampel sebelum dan sesudah treatment dengan Scanning Electron Microscope (SEM, JEOL, JSM-6500 LV). Struktur kristal dari sampel dapat dianalisi dengan $X$-Ray Diffraction (XRD, Rigaku D/MAX-B X-ray diffractometer dengan Copper $\mathrm{K}$-alpha $\left(\mathrm{Cu} \mathrm{K}_{\alpha}\right)$ radiasi pada $40 \mathrm{kV}$ and $100 \mathrm{~mA}$ ) dilakukan sebelum dan sesudah treatment.

Penentuan Crystalline Index (CrI) dihitung dengan cara:

$$
\operatorname{CrI}=\frac{\left(\mathrm{I}_{002}+\mathrm{I}_{\mathrm{am}}\right)}{\mathrm{I}_{002}} 100 \%
$$


Dimana $\quad \mathrm{CrI}=$ Crystalline Index, $\mathrm{I}_{002}=$ Kristal dan $\mathrm{I}_{\mathrm{am}}=$ Amorph

\section{HASIL DAN PEMBAHASAN}

Proses hidrolisis menggunakan asam encer (diluted acid hydrolysis) merupakan proses hidrolisis yang paling konvensional untuk memproduksi etanol dari bahan baku selulosa biomassa (Kusnadi et al., 2009). Terdapat dua tahapan pada proses hidrolisis menggunakan asam encer, tahap pertama sebagian besar hemiselulosa akan terhidrolisis yaitu dengan memutuskan ikatan lignin dan selulosa. Tahap kedua untuk menghidrolisis selulosa sehingga menghasilkan glukosa (Arianie \& Idiawati, 2011). Proses hidrolisis dengan penambahan $\mathrm{H}_{2} \mathrm{SO}_{4}$ encer bertujuan untuk melepas lignin yang terikat pada selulosa yang terikat dalam serat kelapa sawit dan mengubah polisakarida menjadi glukosa (Khairunnisa \& Fatimah, 2012).

\section{Pengaruh Konsentrasi Serat Kelapa Sawit terhadap Kadar Glukosa}

Pada proses ini dilihat pengaruh variasi konsentrasi SKS, yaitu 2,5\%, 5\%, 7,5\%, dan $10 \%$ (w/v) terhadap kadar glukosa yang dihasilkan. Selain itu, konsentrasi SKS juga mempengaruhi terhadap hasil reaksi, untuk itu $\mathrm{pH}$ larutan sebelum dan sesudah hidrolisis diperlukan untuk mengetahui pengaruh $\mathrm{pH}$ selama proses hidrolisis. Perubahan tersebut dapat dilihat pada Tabel 1.

Tabel 1. pH Larutan Sebelum dan Sesudah Hidrolisis

\begin{tabular}{ccc}
\hline \multirow{2}{*}{$\begin{array}{c}\text { Serat Kelapa } \\
\text { Sawit }(\% \mathrm{w} / \mathrm{v})\end{array}$} & $\begin{array}{c}\text { pH Larutan } \\
\text { Hidrolisis }\end{array}$ & $\begin{array}{c}\text { Setelah } \\
\text { Hidrolisis }\end{array}$ \\
\hline 2,5 & 1,12 & 0,80 \\
5,0 & 1,06 & 0,83 \\
7,5 & 0,75 & 0,70 \\
10,0 & 0,85 & 0,78 \\
\hline
\end{tabular}

Nilai $\mathrm{pH}$ larutan setelah hidrolisis lebih rendah dibandingkan sebelum hidrolisis, hal ini dikarenakan adanya penambahan asam sulfat sehingga proses delignifikasi terjadi dan terurainya air menjadi ion $\mathrm{H}^{+}$pada kondisi tekanan dan suhu tinggi saat di dalam reaktor. Sedangkan penambahan konsentrasi serat kelapa sawit tidak berpengaruh terhadap perubahan $\mathrm{pH}$, karena dalam proses hidrolisis serat kelapa sawit hanya terkonversi menjadi glukosa dan tidak menghasil ion $\mathrm{H}^{+}$.

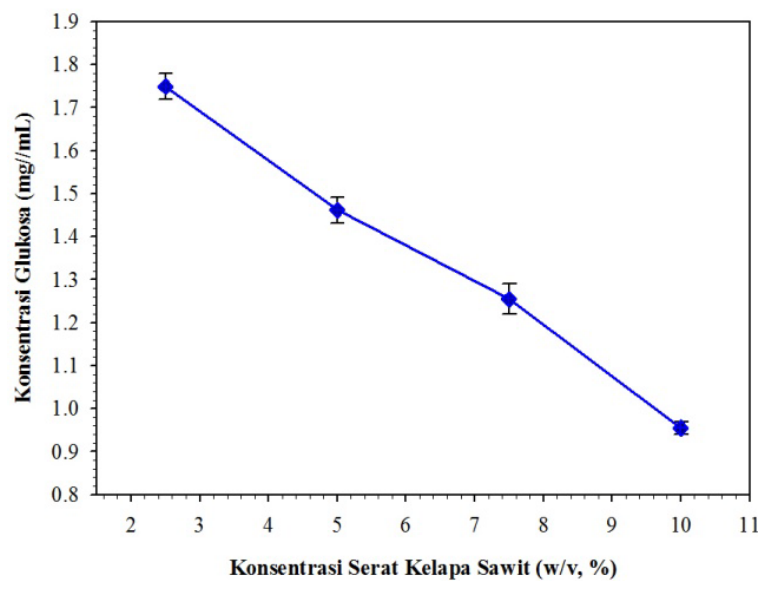

Gambar 1. Hubungan Konsentrasi Serat Kelapa Sawit (\%w/v) dengan Konsentrasi Glukosa (mg/mL) pada proses hidrolisis dengan $\mathrm{t}=2$ jam dan $\mathrm{T}=$ $150{ }^{\circ} \mathrm{C}$.

Dari Gambar 1 pada hidrolisis selama 2 jam dan $150{ }^{\circ} \mathrm{C}$ dapat dilihat konsentrasi glukosa terbesar pada kandungan SKS 2,5\% (w/v) sebesar $1,749 \pm 0,030 \mathrm{mg} / \mathrm{mL}$. Hal ini disebabkan pada keadaan ini kandungan $2 \% \mathrm{H}_{2} \mathrm{SO}_{4}$ bekerja dengan baik, dimana konsentrasi SKS melakukan delignifikasi dan hidrolisis, sedangkan pada konsentrasi SKS 10\% menghasilkan kadar glukosa terkecil karena konsentrasi substrat terlalu banyak sehingga proses delignifikasi dan hidrolisis pada larutan tidak efektif.

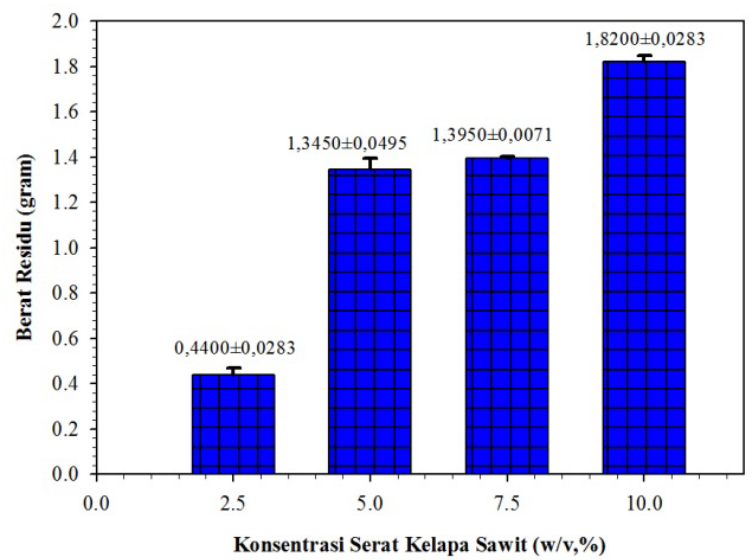

Gambar 2. Hubungan Konsentrasi Serat Kelapa Sawit dengan Berat Residu pada proses hidrolisis dengan $\mathrm{t}=2$ jam dan $\mathrm{T}=150{ }^{\circ} \mathrm{C}$. 
Pengamatan terhadap residu SKS setelah hidrolisis terjadi pengurangan massa, ini disebabkan karena banyaknya massa selulosa yang terhidrolisis menjadi glukosa (Khairunnisa \& Fatimah, 2012). Hal ini dapat dilihat pada Gambar 2, hubungan berat residu memberikan nilai yang terkecil dengan konversi glukosa terbesar.

\section{Pengaruh Waktu Hidrolisis terhadap Kadar Glukosa yang dihasilkan}

Konsentrasi glukosa terbesar pada substrat SKS $2,5 \%$, selanjutnya dilakukan proses hidrolisis dengan variasi waktu untuk mengetahui waktu yang optimal untuk menghasilkan glukosa. Kadar glukosa yang didapat untuk masing-masing variasi waktu dapat dilihat pada Gambar 3. Dari hasil yang diperoleh terjadi peningkatan kadar glukosa seiring lamanya waktu hidrolisis. Kadar glukosa optimum terjadi pada waktu 3 jam sebesar 2,336 \pm $0,015 \mathrm{mg} / \mathrm{mL}$. Hal dimungkinkan karena lamanya waktu proses akan menyebabkan lignin yang terlarut akan semakin banyak dan proses impregnasi antara pelarut dengan serat akan semakin sempurna untuk proses hidrolisis. Untuk waktu reaksi 4 jam memberikan konsentrasi glukosa yang tidak signifikan dari proses 3 jam, hal ini menunjukkan bahwa proses hidrolisis berlangsung optimal selama 3 jam.

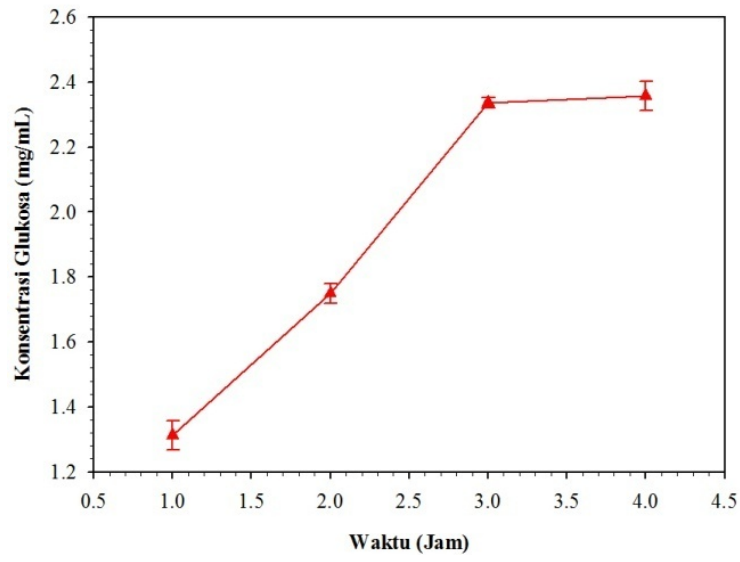

Gambar 3. Hubungan variasi waktu (jam) terhadap kadar glukosa pada proses hidrolisis dengan $\mathrm{T}=150{ }^{\circ} \mathrm{C}$ dan konsentrasi SKS 2,5\% (w/v).

\section{Karakteristik Serat Kelapa Sawit Sebelum dan Sesudah Hidrolisis}

Serat kelapa sawit sebelum dan setelah proses hidrolisis mengalami perubahan warna dari coklat muda menjadi coklat gelap dan teksturnya lebih kasar. Hal ini menunjukkan bahwa lignin telah mengalami kerusakan, selain itu hal ini juga disebabkan karena selulosa terdestruksi menjadi glukosa. Hasil uji SEM pada SKS sebelum dan sesudah hidrolisis dapat dilihat pada Gambar 4. Dari gambar 4 (a dan b) terlihat bahwa struktur SKS serat panjang, sebelum proses treatment struktur SKS halus dan tidak pecah. Hal ini dikarenakan struktur lignin pada selulosa belum mengalami kerusakan. Berbeda dengan struktur SKS setelah proses hidrolisis (Gambar 4(c,d)), permukaan SKS terlihat lebih kasar. Hal ini menunjukkan bahwa struktur lignin rusak setelah mengalami pemanasan pada suhu tinggi dan adanya $\mathrm{H}_{2} \mathrm{SO}_{4}$ yang berperan untuk menghilangkan komponen-komponen yang mengikat selulosa pada SKS. Berdasarkan hal di atas dapat disimpulkan bahwa penambahan $\mathrm{H}_{2} \mathrm{SO}_{4}$ membantu proses hidrolisis selulosa menjadi glukosa pada SKS yang terikat oleh lignin.

Selain dilakukan uji terhadap struktur morfologinya, dilakukan pula uji berdasarkan kristalinitas dari masing-masing sampel. Dari Tabel 2 dapat dilihat intensitas serat kelapa sawit sebelum dan sesudah proses hidrolisis dan profil XRD dari SKS sebelum dan sesudah hidrolisis menggunakan $\mathrm{H}_{2} \mathrm{SO}_{4}$ dapat dilihat pada Gambar 5 .

Dari Tabel 2 dapat dilihat bahwa crystalline index SKS sebelum proses hidrolisis sebesar $27,57 \%$ yang mengindikasikan bagian amorph (hemiselulosa dan lignin) dari sampel masih relatif tinggi dibandingkan bagian kristalinnya, sedangkan setelah dilakukan proses hidrolisis terjadi peningkatan intensitas menjadi $31,15 \%$. Dengan kata lain kristalinitas setelah treatment meningkat sebesar 3,58\%. Hal ini menunjukkan bahwa kristal (selulosa) semakin tinggi, karena terjadi perusakan struktur lignin selama proses delignifikasi (Rodiansono et al., 2013).

Tabel 2. Karakterisasi Peak Serat Kelapa Sawit sebelum dan sesudah Treatment.

\begin{tabular}{|c|c|c|c|}
\hline \multirow[b]{2}{*}{$\begin{array}{c}\text { Sampel } \\
\text { SKS }\end{array}$} & \multicolumn{2}{|c|}{ Karakteristik Peak } & \multirow{2}{*}{$\begin{array}{c}\text { Crystalline } \\
\text { Index } \\
\text { (CrI, \%) }\end{array}$} \\
\hline & $\begin{array}{c}\text { Amorph } \\
\left(18,7^{\circ}\right)\end{array}$ & $\begin{array}{l}\text { Kristal } \\
\left(22,4^{\circ}\right)\end{array}$ & \\
\hline $\begin{array}{l}\text { sebelum } \\
\text { treatment }\end{array}$ & 268 & 370 & 27,57 \\
\hline $\begin{array}{l}\text { sesudah } \\
\text { treatment }\end{array}$ & 495 & 719 & 31,15 \\
\hline
\end{tabular}




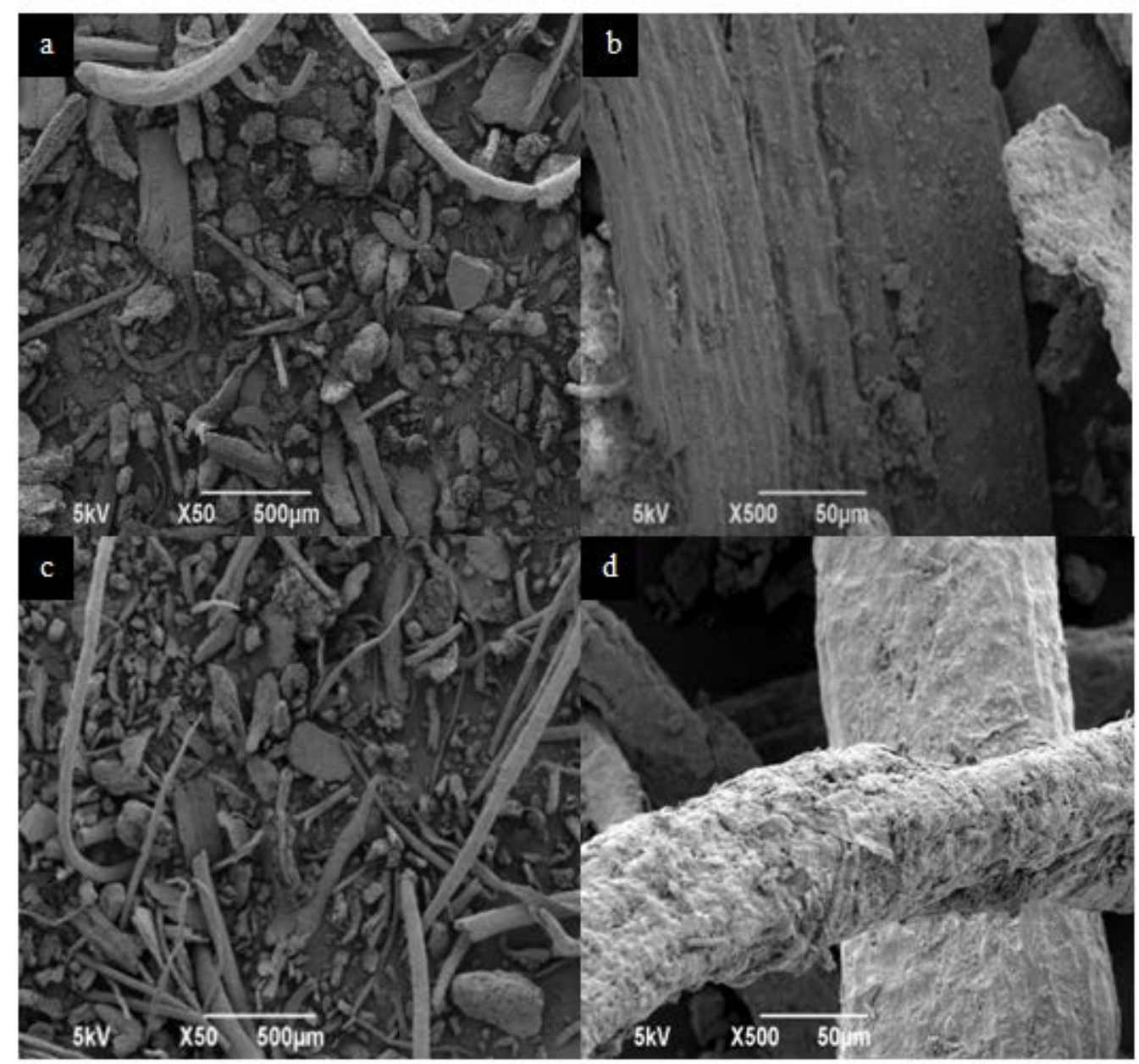

Gambar 4. SEM images dari SKS (a) SKS sebelum treatment perbesaran 50x; (b) SKS sebelum treatment perbesaran 500x; (c) SKS setelah treatment perbesaran 50x; (d) SKS setelah treatment $500 \mathrm{x}$

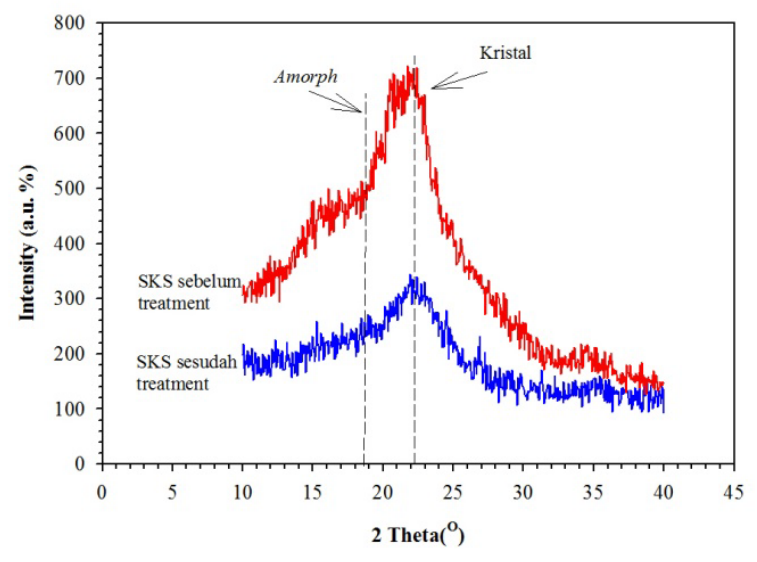

Gambar 5. X-Ray Diffraction Serat Kelapa Sawit untuk FC dan FC-treatment pada $\mathrm{T}=$ $150^{\circ} \mathrm{C}$ pada Proses Hidrolisis dengan $\mathrm{H}_{2} \mathrm{SO}_{4} 2 \%$ (v/v).

Pada Gambar 5 menunjukkan profil difraktogram SKS sebelum dan sesudah hidrolisis, dimana memiliki memiliki dua puncak yang spesifik di $2 \theta=18,7^{\circ}$ (selulosa I), $22,4^{\circ}$ (selulosa II) untuk sellulosa (Yu et al., 2008). Kedua puncak mengindikasikan berturut-turut bagian amorph dan kristalin. Analisa XRD ini dilakukan untuk mengetahui struktur kristal selulosa dan mengetahui Indeks kristalinitas (CrI) sebelum dan sesudah treatment. Dapat disimpulkan bahwa acid treatment telah merusak struktur lignin dari serat kelapa sawit dan selanjutnya dengan reaksi hisrolisis mengkonversi selulosa menjadi glukosa.

\section{SIMPULAN}

Dari hasil penelitian yang telah dilakukan dapat disimpulkan bahwa proses dilute-acid hidrolisis dengan reaktor hydrothermal dapat mengkonversi serat kelapa sawit menjadi glukosa. Kondisi operasi yang optimum pada suhu $150{ }^{\circ} \mathrm{C}$ selama 3 jam dengan loading serat kelapa sawit 2,5\% (w/v). Struktur morfologi dari serat kelapa sawit setelah hydrothermal treatment menjadi pecah 
dan kasar, hal ini diikuti dengan meningkatnya crystalline index dari selulosa dari $27,57 \%$ menjadi $31,15 \%$. Larutan glukosa yang dihasilkan dapat dkembangkan menjadi bahan dasar pembuatan bioetanol.

\section{DAFTAR PUSTAKA}

Arianie, L., Idiawati, N. 2011. Penentuan Kadar Lignin dan Kadar Glukosa dalam Hidrolisis Organosolv dan Hidrolisis Asam. FMIPA Universitas Tanjungpura, Pontianak.

Boussarsar, H., Rogé, B., Mathlouthi, M. 2009. Optimization of sugarcane bagasse conversion by hydrothermal treatment for the recovery of xylose. Bioresource Technology, 100, 6537-6542.

ICN. 2011. Industri Palm Oil Indonesia. Profil Industri Palm Oil Indonesia.

Karakashev, D., Thomsen, A.B., Angelidaki, I. 2007. Anaerobic Biotechnological Approaches for Production of Liquid Energy Carriers from biomass. Biotechnol. Lett., 29 1005-1012.

Khairunnisa, Fatimah. 2012. Konversi dan Karakterisasi Limbah Serat Kelapa Sawit (fiber cake) dengan Acid Hydrolisis Via
Hydrothermal Treatment Sebagai Bahan Baku Bioetanol. Laporan Penelitian, Program Studi Teknik Kimia, Universitas Lambung Mangkurat.

Kusnadi, Syulasmi, A., Adisenjaya, Y.H. 2009. Pemanfaatan Sampah Organik Sebagai Bahan baku Produksi Bioetanol Sebagai Energi Alternatif. Laporan Penelitian Strategi Nasional. Universitas Pendidikan Indonesia. Bandung.

Rodiansono, Utami, U.B.L., Widyastuti, N., Wulandari, P.C., Risnawati, I. 2013. Hidrolisis Lignoselulosa dari Tandan Kosong Kelapa Sawit Menggunakan Katalis Asam Karboksilat. FMIPA Kimia Universitas Lambung Mangkurat: Banjarbaru.

Rosdanelli, Daud, W.R.W. 2004. Through drying of oil palm empty fruit bunches (EFB) fiber using superheated steam. Silva, M.A., Rocha, S.C.S., Mujumdar A.M., eds.; University of Campinas: Campinas, Brazil., 2027-2034.

Sluiter. 2006. Bioetanol Sebagai Sumber Energi.

Yu, Y., Lou, X., Wu, H. 2008. Some Recent Advances in Hydrolysis of Biomass in Hot-Compressed Water and Its Comparisons with Other Hydrolysis Methods. Energy and Fuels, 22, 46-60. 